\title{
DEVELOPMENT OF TEST PROTOCOLS FOR THE ANALYSIS OF MAGNETO-RHEOLOGICAL PROPERTIES OF FIELD-RESPONSIVE BITUMINOUS BINDERS
}

\author{
Ezio Santagata, Orazio Baglieri, Lucia Tsantilis and Arianna Vercelli \\ Department of Environment, Land and Infrastructure Engineering, Politecnico di Torino, Turin, Italy
}

Received 2013-11-11; Revised 2013-11-27; Accepted 2014-01-20

\begin{abstract}
Magneto-rheological fluids are materials that exhibit a significant change in their rheological properties in the presence of a magnetic field. Because of such a field-dependent behavior, they can act as smart materials in applications in which changeable performances are desired. In road pavement engineering, the use of bitumen-based magneto-rheological fluids may open innovative scenarios related to the construction of smart pavement sections and to the investigation of damage mechanisms in binders and mixtures. The research work presented in this study explored magneto-rheological properties of several field-responsive bituminous binders obtained from two different base bitumens combined with multi-wall carbon nanotubes and powder iron. The experimental program included oscillatory shear loading tests at different temperatures, performed in the strain controlled mode by means of a dynamic shear rheometer equipped with a magneto-rheological device. The investigation was carried out with the specific goal of identifying critical issues which should be taken into account in materials preparation, testing procedures and data analysis. Undesired overheating of specimens during testing was identified and taken into account for a correct interpretation of experimental data. Thus, while the field-sensitivity of carbon nanotubes was found to be negligible as a result of the magnetic shielding action of bitumen, it was shown that powder iron can significantly affect the magneto-rheological properties of bituminous binders when employed in sufficiently high amounts. Moreover, obtained results indicated that selection of base bitumen is a key factor in designing bituminous-based smart materials. Practical implications which derive from the study are mainly relative to the fine-tuning of laboratory characterization procedures which should necessarily overcome current limitations in temperature regulation and magnetic field generation. Experimental data presented in this study also suggest that future development of pavement magnetic sensing techniques should consider the combined effects of temperature and field intensity.
\end{abstract}

Keywords: Magneto-Rheology, Bituminous, Smart Materials, Carbon Nanotubes, Powder Iron

\section{INTRODUCTION}

Magneto-rheological fluids are materials that exhibit a significant change in their rheological properties in the presence of a magnetic field. This is due to their peculiar internal structure which consists in a stable dispersion in a base fluid of field-responsive molecules or particles that can be polarized and aligned with field direction (Phule, 2001; Kciuk and Turczyn, 2006; Kamila, 2013).
Rheological properties which have been reported to be sensitive to magnetic fields for this type of material include yield stress, shear viscosity and complex modulus. Observed changes occur instantaneously, are typically dependent upon magnitude of external magnetic field and are totally reversible (Wen et al., 2008; Choi and Jhon, 2009; Fang et al., 2009; Kang et al., 2011).

As a result of the phenomena described above, an increasing amount of research has been carried out in recent

Corresponding Author: Ezio Santagata, Department of Environment, Land and Infrastructure Engineering, Politecnico di Torino, Turin, Italy 
years in the development of magneto-rheological fluids to be used as smart materials in a wide range of commercial fields, such as automotive industry (Sakai, 1988; Carlson and Sproston, 2000; Klingenberg, 2001; Huang et al., 2002), polishing industry (Kordonski and Golini, 1999; Kim et al., 2004; Singh et al., 2004), medicine (Ellis, 2011) and information technology (Liu et al., 2005).

The introduction of bitumen-based magnetorheological fluids in road pavementsmight open new scenarios related to the construction of smart pavement sections. The main application that seems to have the potentiality to be implemented at full scale consists in the development of innovative monitoring systems. Pavement layers constituted by bitumen-based smart materials may work as sensors, in replacement of traditional devices installed in the pavement (Xue et al., 2012). Other possible applications are related to the opportunity of investigating damage mechanisms of bituminous binders and mixtures by integrating traditional measurement techniques with the application of magnetic fields in controlled conditions.

In the research work presented in this study, the development of bitumen-based smart materials was explored by investigating the magneto-rheological properties of several laboratory-prepared blends obtained from two different base bitumens combined with commercially available multi-wall carbon nanotubes and powder iron. The experimental program included oscillatory shear loading tests at various temperatures carried out by means of a dynamic shear rheometer equipped with a magneto-rheological device.

Given the preliminary nature of the study, the experimental work was carried out with the specific goal of identifying critical issues which should be taken into account in materials preparation, testing procedures and data analysis.

On the basis of the obtained results, propertiesof bitumen-based smart materials were analyzed and discussed.

\section{MATERIALS AND METHODS}

\subsection{Bituminous Binders}

Neat bitumensemployed in the investigation were two commercially available products, marked as " $\mathrm{A}$ " and "B", classified as PG58-22 and PG70-22, respectively, according to the SUPERPAVE performance grading system (AASHTO, 2010). Composition of the binders was assessed by referring to the classical colloidal dispersion model (Nellensteyn, 1928) by means of the combined use of Thin Layer Chromatography and Flame Ionization Detection (Lesueur, 2009; Santagata et al.,
2009). Results of such analyses, expressed in terms of percentages of saturates, aromatics, resins and asphaltenes, are given in Table $\mathbf{1 .}$

Since no previous experimental work was found in literature on the topic of bitumen magneto-rheology, choice of additives to consider in the study was based on the analysis of research experiences documented for other types of field-sensitive smart materials (Fang et al., 2009; Kang et al., 2011; Pu et al., 2006; Hwang et al., 2011). As a result of this preliminary evaluation, the investigation focused on the use of two additives characterized by completely different physical and chemical properties: Powder Iron (PF) and Carbon Nanotubes (CNTs). While the former additive is absolutely innovative for bituminous applications, in the case of CNTs quite a few research studiesin recent yearshave evaluatedtheir capability of improvingperformance properties of bitumen (Xiao et al., 2011; Amirkhanian et al., 2011a; 2011b; Santagata et al., 2012; 2013; Motlagh et al., 2012; Boyer and Barrera, 2013).

Employed PF, characterized by a purity level of more than $95 \%$, was entirely passing the ASTM $0.180 \mathrm{~mm}$ sieve. CNTs were high carbon purity $(>90 \%)$ multiwall cylinders produced by means of the Catalyzed Chemical Vapour Deposition (CCVD) technique, with an average aspect ratio of 157.9. Main physical characteristics of the two additives are summarized in Table 2.

Bitumen-additive blends were prepared in the laboratory by adding PF and CNTs to the two neat binders, which were previously heated at $160^{\circ} \mathrm{C}$ to reach a sufficiently fluid state. An acceptable dispersion of the particles in the bituminous matrix was thereafter obtained by thoroughly mixing the blends.

Different percentages (by weight of base bitumen) were adopted for the two additives due to their different density and specific surface, which significantly affect the interaction phenomena that may arise between the two phases. In the case of PF, chosen dosages were equal to 20 and $40 \%$. Following the experience of previous investigations (Santagata et al., 2012; 2013), CNTs, characterized by a higher unit volume, were employed in percentages equal to 1 and $3 \%$.

With the purpose of avoiding spurious effects that may occur during aging treatments, all blends were tested only in their original state.

\subsection{Magneto-Rheologicaltests}

Magneto-Rheological Tests (MRTs) were performed by making use of a dynamic shear rheometer (Physica MCR301) equipped with a magneto-rheological device (Physica MRD 70/1T) and connected to an external refrigeration system (Lauda Re207) for temperature regulation. 
Table 1. Composition of neat bitumens

\begin{tabular}{lcc}
\hline & Bitumen A & Bitumen B \\
\hline Saturates (\%) & 5.5 & 4.6 \\
Aromatics (\%) & 38.1 & 62.0 \\
Resins (\%) & 42.0 & 13.1 \\
Asphaltenes (\%) & 14.4 & 20.3 \\
\hline
\end{tabular}

Table 2. Characteristics of the additives

\begin{tabular}{lll}
\hline & PF & CNTs \\
\hline Density $\left[\mathrm{g} / \mathrm{cm}^{3}\right]$ & 7.86 & 0.0427 \\
Specific surface $\left[\mathrm{m}^{2} / \mathrm{g}\right]$ & 0.2 & $250-300$ \\
Electric conductivity $[\mathrm{S} / \mathrm{m}]$ & $9.96 \times 10^{6}$ & $10^{4}$ \\
Thermal conductivity $[\mathrm{W} /(\mathrm{mK})]$ & 80.2 & 3000 \\
\hline
\end{tabular}

Adoption of a magneto-rheological device allows the rheological properties of a material to be evaluated in the presence of a magnetic field (B). Passage of an electric current (I) in the inductive coils inside the device chamber generates a magnetic field that is perpendicular to the coil surface and proportional to electric current. Actual values of the induced magnetic field aremonitored by employing a gaussmeter, the probe of which is directly located beneath the measuring system.

Tests on binders were carried out by making use of a $20 \mathrm{~mm}$ parallel plate sensor system (PP20), with a $1 \mathrm{~mm}$ gap between the plates. Since magnetic fluids can be affected by normal field instability phenomena which lead to the formation of spikes in free surfaces perpendicular to the field direction (Rinaldi et al., 2005), an upper plate with a specially-designed groove on its outer perimeter was employed for testing. Thus, the presence of free surface in the region with a strong magnetic field was limited and during testing possible pulling out of the specimen from the measurement gapwas prevented.

Since the presence of a groove at the periphery of the plates does not permit trimming operations, the standard protocol (Petersen et al., 1994) usually adopted for sample preparation was modified. Mass of the binder necessary to fill the volume between the plates was calculated by relying on density measurements performed with the capillary-stoppered pyknometer method (EN, 2009). Subsequently, the exact required mass of the binder was poured into a latex cylindrical mould and, after cooling to ambient temperature, the resulting specimen was sandwiched between the plates of the measuring system which were previously heated in order to prevent adhesion ruptures at the binder-steel interfaces. Prior to starting each test, samples were conditioned at test temperature for 30 minutes to avoid drawbacks related to the occurrence of temperature gradients within their volume.
Table 3. MRT steps

\begin{tabular}{lll}
\hline Step & Current [A] & Magnetic field [T] \\
\hline 1 & 0.0 & 0.0 \\
2 & 2.5 & 0.4 \\
3 & 5.0 & 0.8 \\
4 & 2.5 & 0.4 \\
5 & 0.0 & 0.0 \\
\hline
\end{tabular}

Table 4. Testing program

\begin{tabular}{lllll}
\hline & MRTs & & TRs & \\
& ------- & ---- \\
Binder code & $34^{\circ} \mathrm{C}$ & $65^{\circ} \mathrm{C}$ & $34^{\circ} \mathrm{C}$ & $65^{\circ} \mathrm{C}$ \\
\hline A & $\times$ & $\times$ & $\times$ & $\times$ \\
B & $\times$ & $\times$ & $\times$ & $\times$ \\
A_1\%CNT & $\times$ & & $\times$ & \\
A_3\%CNT & $\times$ & $\times$ & $\times$ & $\times$ \\
B_3\%CNT & & $\times$ & & $\times$ \\
A_20\%PF & $\times$ & & $\times$ & \\
A_40\%PF & $\times$ & $\times$ & $\times$ & $\times$ \\
B_40\%PF & & $\times$ & & $\times$ \\
\hline
\end{tabular}

With the aim of studying the effect of magnetic fields on the viscoelastic properties of bitumenscontaining field-sensitive additives, storage and loss moduli $\left(\mathrm{G}^{\prime}\right.$ and G”) were determined at reference values of angular frequency and temperature, by varying the electric current passing in the coils of the magnetic device.

Angular frequency was set at $10 \mathrm{rad} / \mathrm{s}$, which was assumed to be representative of normal traffic loading in road pavements (Bahia et al., 2001). Influence of test temperature was taken into account by considering the two values $\left(34\right.$ and $\left.65^{\circ} \mathrm{C}\right)$ corresponding to the instrumental limits of the employed equipment.

Storage and loss moduli were monitored by applying $1 \%$ oscillatory sinusoidal strain, which was comprised within the linear viscoelastic region of all blends.

Electric current was applied in discrete steps up to the maximum value which can be controlled by the device (equal to $5 \mathrm{~A}$ ) and back down to zero, thus subjecting test specimens to magnetic loops. Each step was preceded by 5 min conditioning to achieve a stationary magnetic field within the specimen. Testing steps are summarized in Table 3, which shows values of imposed electric current and of generated magnetic field.

\subsection{Temperature Ramps}

Temperature Ramps (TRs) were carried out in the absence of any magnetic field by making use of the same dynamic shear rheometer employed for MRTs. As explained in detail in the discussion section of the study, this was done to assess the existence of undesired overheating effects during MRTs. 
TRs were performed in steps of $0.1^{\circ} \mathrm{C}$, covering a narrow range (of approximately $1^{\circ} \mathrm{C}$ ) around target temperatures chosen for MRTs. For each step, after 5 minutes conditioning, oscillatory shear loads were applied to specimens with the same angular frequency (10 rad/s) and strain (1\%) adopted in MRTs. Each TR was composed of an increasing and a decreasing ramp. Storage and loss moduli obtained in the two ramps, were averaged and thereafter considered for analysis.

\subsection{Testing Program}

The testing program covered by the investigation is synthesized in Table 4. Based on their composition, binders were associated to a code of the general form X_D\%T, where " $\mathrm{X}$ " identifies base bitumen (A or B), "D\%" refers to additive dosage $(20,40,1$ or 3 , depending upon the case) and " $\mathrm{T}$ " indicates additive type (PF or CNT).

The two neat binders were subjected to MRTs and TRs at both temperatures. Effects associated to variations of additive dosage were evaluated at $34^{\circ} \mathrm{C}$ by considering blends prepared with base binder $\mathrm{A}$. The role played by base bitumen was highlighted by means of tests at $65^{\circ} \mathrm{C}$ on blends with the higher additive dosage.

\section{RESULTS}

Results of MRTs and TRs, expressed in terms of storage and loss moduli (G' and G'), are respectively given in Table 5-8 and Fig. 1 and 2.

Supplementary data were gathered from MRTs by considering temperature and magnetic field intensity values measured by the two probes located within the testing apparatus. In both cases, differences from target values were recorded. This is shown in Table 9, which contains, for each measuring step, actual variation ranges $(\Delta \mathrm{T}$ and $\Delta \mathrm{B})$ derived from tests carried out on all the binders.

Table 5. Average G' values (in $\mathrm{kPa}$ ) obtained from MRTs performed at $34^{\circ} \mathrm{C}$

\begin{tabular}{|c|c|c|c|c|c|}
\hline \multirow[b]{2}{*}{ Binder code } & \multicolumn{5}{|c|}{ Test step } \\
\hline & $1 \mathrm{st}$ & 2nd & $3 \mathrm{rd}$ & 4th & 5 th \\
\hline $\bar{A}$ & 37.4 & 32.6 & 16.7 & 22.3 & 29.60 \\
\hline B & 134.0 & 119.8 & 69.8 & 84.6 & 108.40 \\
\hline A_1\%CNT & 50.5 & 44.2 & 24.0 & 31.4 & 40.70 \\
\hline A_3\%CNT & 261.7 & 238.7 & 160.4 & 189.7 & 229.50 \\
\hline A_20\%PF & 41.4 & 38.0 & 20.8 & 25.9 & 33.93 \\
\hline A_40\%PF & 58.7 & 82.4 & 59.1 & 69.8 & 51.90 \\
\hline
\end{tabular}

Table 6. Average G" values (in $\mathrm{kPa}$ ) obtained from MRTs performed at $34^{\circ} \mathrm{C}$

\begin{tabular}{|c|c|c|c|c|c|}
\hline \multirow[b]{2}{*}{ Binder code } & \multicolumn{5}{|c|}{ Test step } \\
\hline & $1 \mathrm{st}$ & 2nd & $3 \mathrm{rd}$ & 4th & 5 th \\
\hline$\overline{\mathrm{A}}$ & 132.8 & 120.6 & 73.4 & 90.8 & 111.8 \\
\hline B & 267.4 & 247.0 & 166.7 & 192.4 & 229.8 \\
\hline A_1\%CNT & 152.1 & 138.0 & 86.9 & 106.5 & 129.4 \\
\hline A_3\%CNT & 331.1 & 308.7 & 218.9 & 253.7 & 298.2 \\
\hline A_20\%PF & 137.5 & 127.0 & 78.0 & 94.1 & 119.4 \\
\hline A_40\%PF & 162.2 & 180.3 & 116.9 & 144.3 & 149.8 \\
\hline
\end{tabular}

Table 7. Average G' values (in $\mathrm{kPa}$ ) obtained from MRTs performed at $65^{\circ} \mathrm{C}$

\begin{tabular}{|c|c|c|c|c|c|}
\hline \multirow[b]{2}{*}{ Binder code } & \multicolumn{5}{|c|}{ Test step } \\
\hline & $1 \mathrm{st}$ & 2 nd & $3 \mathrm{rd}$ & 4 th & 5 th \\
\hline$\overline{\mathrm{A}}$ & 0.09 & 0.08 & 0.04 & 0.05 & 0.07 \\
\hline B & 0.36 & 0.32 & 0.20 & 0.21 & 0.29 \\
\hline A_3\%CNT & 39.27 & 36.94 & 31.55 & 33.66 & 34.47 \\
\hline B_3\%CNT & 39.57 & 36.37 & 32.12 & 32.01 & 32.95 \\
\hline A_40\%PF & 0.19 & 7.41 & 9.68 & 7.67 & 0.20 \\
\hline B_40\%PF & 0.38 & 25.66 & 33.34 & 25.96 & 0.55 \\
\hline
\end{tabular}


Ezio Santagata et al. / American Journal of Applied Sciences 11 (3): 505-519, 2014

Table 8. Average G" values (in $\mathrm{kPa}$ ) obtained from MRTs performed at $65^{\circ} \mathrm{C}$ Test step

\begin{tabular}{|c|c|c|c|c|c|}
\hline \multirow[b]{2}{*}{ Binder code } & \\
\hline & $1 \mathrm{st}$ & 2 nd & $3 \mathrm{rd}$ & 4th & 5 th \\
\hline $\mathrm{A}$ & 1.69 & 1.56 & 1.05 & 1.23 & 1.48 \\
\hline B & 3.43 & 3.14 & 2.27 & 2.38 & 2.91 \\
\hline A_3\%CNT & 29.02 & 27.68 & 22.23 & 23.79 & 26.33 \\
\hline B_3\%CNT & 24.33 & 24.78 & 20.21 & 20.14 & 21.71 \\
\hline A_40\%PF & 2.47 & 4.73 & 4.62 & 4.16 & 2.35 \\
\hline В $40 \% \mathrm{PF}$ & 3.44 & 18.83 & 19.49 & 15.03 & 3.82 \\
\hline
\end{tabular}

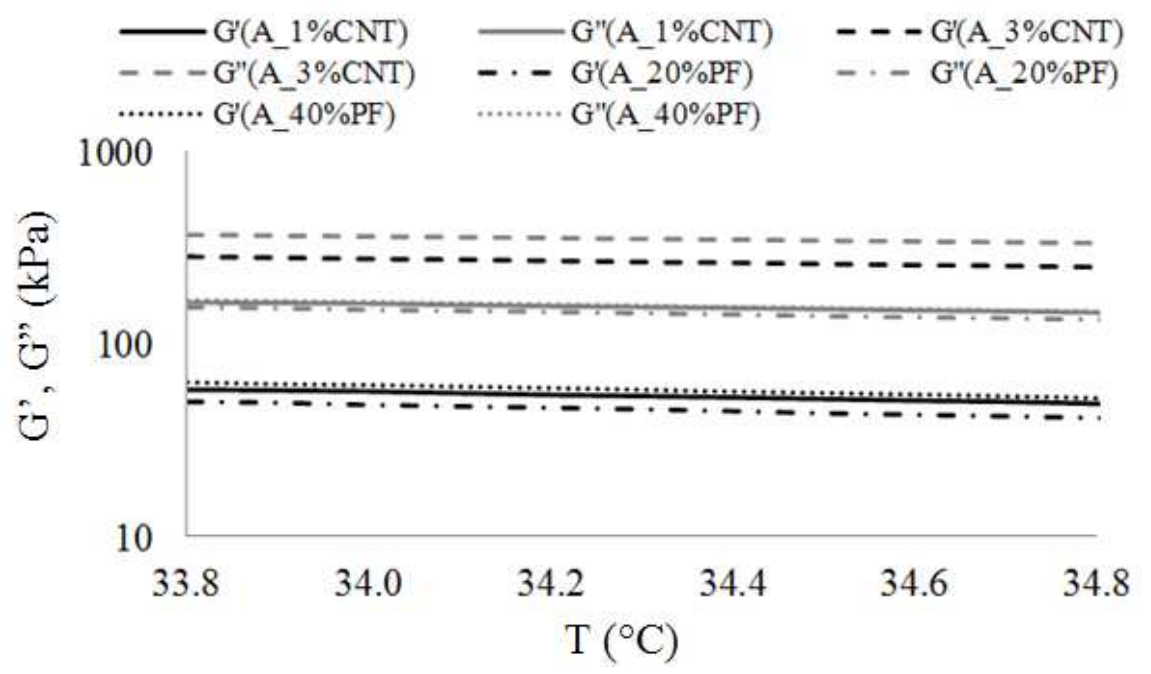

Fig. 1. Average G' and G" values obtained from TRs

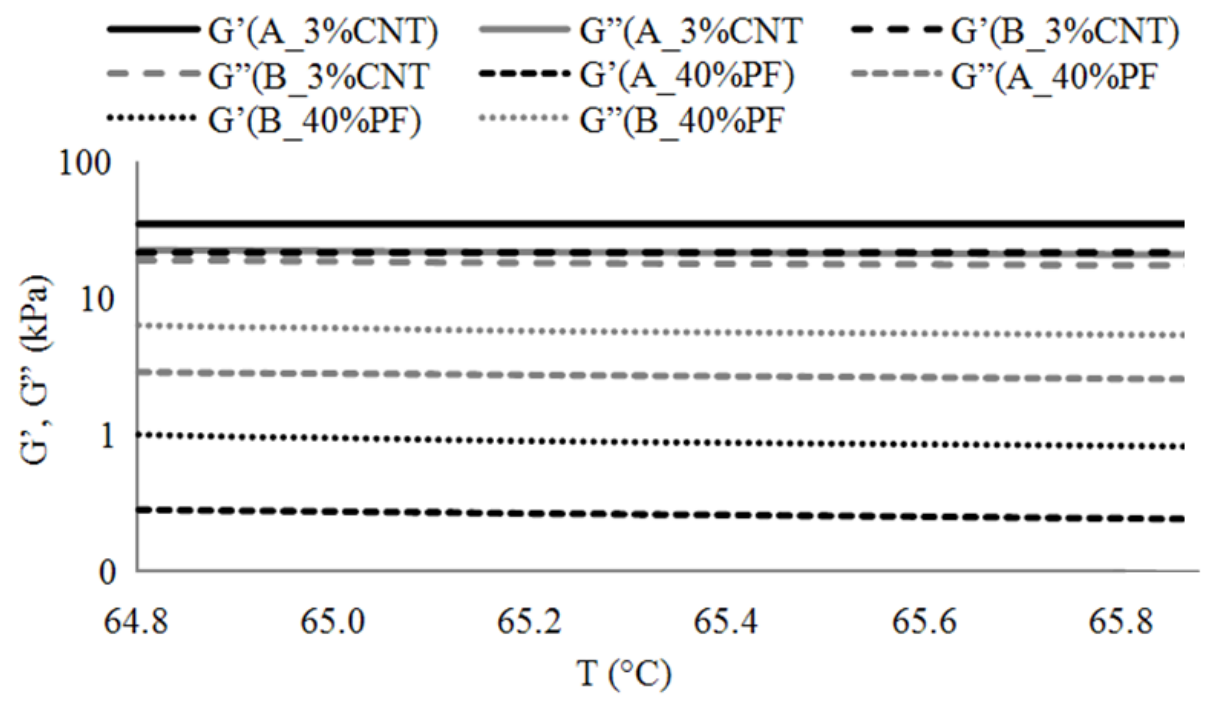

Fig. 2. Average G' and G" values obtained from TRs performed around $65^{\circ} \mathrm{C}$ 


\section{DISCUSSION}

\subsection{Biasing Temperature Variations}

By analyzing results of MRTs carried out on neat binders, it was observed that the storage and loss moduli seemed to be affected by variations in magnetic field at both test temperatures (Fig. 3-6) which refer to bitumen B. An increase or a decrease in electric current generated a reduction or a growth, respectively, of modulus values. Moreover, non-negligible differences were recorded between data obtained for the same electric current intensity but at different steps of each test (1st step versus 5th and 2nd step versus 4 th).

In view of the fact that MRT measurements were performed in the linear viscoelastic region and that neat bitumen should not be affected by the presence of a magnetic field, the occurrence of specimen overheating phenomena was hypothesized to explain such results.

Maximum deviations $(|\delta \mathrm{T}|)$ from target test temperature were derived from data reported in Table 9. As shown in Fig. 7, peak deviation (equal to $0.75^{\circ} \mathrm{C}$ ) was recorded during step 3 , which is associated to the highestimposed electric current. Moreover, by comparing steps with the same electric current $\left(1^{\text {st }}\right.$ step versus $5^{\text {th }}$ and $2^{\text {nd }}$ step versus $4^{\text {th }}$ ) it was found that, as a consequence of thermal inertia, undesired heating effects were more significant in the second part of the MRTs (with decreasing values of imposed magnetic field).

With the purpose of excluding these overheating effects from analysis, thus obtaining adjusted values of storage and loss moduli $\left(\mathrm{G}_{\mathrm{C}}, \mathrm{G}_{\mathrm{C}}{ }_{\mathrm{C}}\right)$, a simple correction was made with the aid of data collected from temperature ramps (Fig. 1 and 2). Hence, measured values of storage and loss moduli $\left(\mathrm{G}_{\mathrm{M}}, \mathrm{G}_{\mathrm{M}}{ }_{\mathrm{M}}\right)$ were corrected to take into account changes in modulus values $\left(\Delta \mathrm{G}_{\Delta \mathrm{T}_{-} \mathrm{R}}, \quad \Delta \mathrm{G}^{\prime \prime}{ }_{\Delta \mathrm{T}_{-} \mathrm{R}}\right)$ caused by the variations in temperature recorded throughout the steps of each test (Equation 1 and 2):

$$
\begin{aligned}
& \mathrm{G}_{\mathrm{C}}{ }^{\prime}=\mathrm{G}_{\mathrm{M}}{ }_{\mathrm{M}}+\Delta \mathrm{G}^{\prime}{ }_{\Delta \mathrm{T}_{-} \mathrm{R}} \\
& \mathrm{G}^{\prime \prime}{ }_{\mathrm{C}}=\mathrm{G}^{\prime \prime}{ }_{\mathrm{M}}+\Delta \mathrm{G}{ }_{\Delta \mathrm{T}_{-} \mathrm{R}}
\end{aligned}
$$

Figure 8-11 provide examples of results obtained for binder Aby means of the above described correction. Similar results were recorded for binder B.

It can be noticed that the effect of temperature variations recorded by the equipment was not sufficient to explain the evolution of rheological properties found during testing. In fact, corrected modulus values $\left(\mathrm{G}_{\mathrm{C}}\right.$,
G" ${ }_{C}$ ) were not constant as a function of the applied magnetic field and were clearly lower than expected target values $\left(\mathrm{G}_{\mathrm{T}}, \mathrm{G}^{\prime}{ }_{\mathrm{T}}\right)$.

\subsection{Unrecordedtemperature Deviations}

Unexpected results shown in Fig. 8-11 can be explained by considering the position of the temperature probe in the test equipment. The small distance of the probe from the specimen and its proximity to the refrigeration system may in fact justify the existence of unrecorded deviations from target temperature.

By neglecting thermal effects caused by the presence of additives, the above mentioned unrecorded temperature deviation was assumed to be constant since the same protocol was adopted for all tests. Thus, temperature variations which in neat bitumens would lead to the equality between corrected and target modulus values were calculated. These temperature variations were then employed for the evaluation of corresponding modulus changes $\left(\Delta \mathrm{G}^{\prime}{ }_{\Delta \mathrm{T}_{-} \mathrm{U}}, \Delta \mathrm{G}^{\prime}{ }_{\Delta \mathrm{T}_{-} \mathrm{U}}\right)$ of all blends. Consequently, storage and loss moduli $\left(\mathrm{G}_{\mathrm{CC}}\right.$, $\mathrm{G}{ }_{\mathrm{CC}}$ ) were expressed as indicated in Equation 3 and 4:

$\mathrm{G}_{\mathrm{CC}}^{\prime}=\mathrm{G}_{\mathrm{C}^{\prime}}+\Delta \mathrm{G}^{{ }^{\prime} \mathrm{T}_{-} \mathrm{U}}$
$\mathrm{G}^{\prime{ }_{\mathrm{CC}}}=\mathrm{G}^{\prime \prime}{ }_{\mathrm{C}}+\Delta \mathrm{G}^{\prime \prime}{ }_{\Delta \mathrm{T}_{-} \mathrm{U}}$

Examples of corrected moduli obtained with such a procedureare shown in Fig. 12-15, where they are compared with raw data $\left(\mathrm{G}_{\mathrm{M}}, \mathrm{G}_{\mathrm{M}}\right)$ and with those calculated consideringoverheatingeffects $\left(\mathrm{G}_{\mathrm{C}}{ }_{\mathrm{C}}, \mathrm{G}{ }_{\mathrm{C}}\right)$.

It can be observed that differences between results obtained at different steps but at the same current intensity were substantially reduced for all considered blends. This observation suggests that data corrected according to Equation 3 and 4 are indeed characterized by an improved reliability.

\subsection{Additive and Dosage Effects}

By focusing on data corrected as indicated in paragraphs 4.1 and 4.2 it was possible to highlight the true effects of different additives and dosages on the magneto-rheological behavior of bitumens.

It was observed that at $34^{\circ} \mathrm{C}$ the employed lower additive dosages (1\% CNTs and 20\% PF) did not lead to any appreciable variation of rheological properties in the presence of magnetic fields, thus highlighting the magnetic shielding action provided by bitumen (Fig. 1215). When considering blends prepared with the higher dosages (3\% CNTs and 40\% PF), different conclusions were drawn for the two adopted additives. 
Ezio Santagata et al. / American Journal of Applied Sciences 11 (3): 505-519, 2014

Table 9. Temperature (T) and magnetic field intensity (B) ranges recorded during MRTs

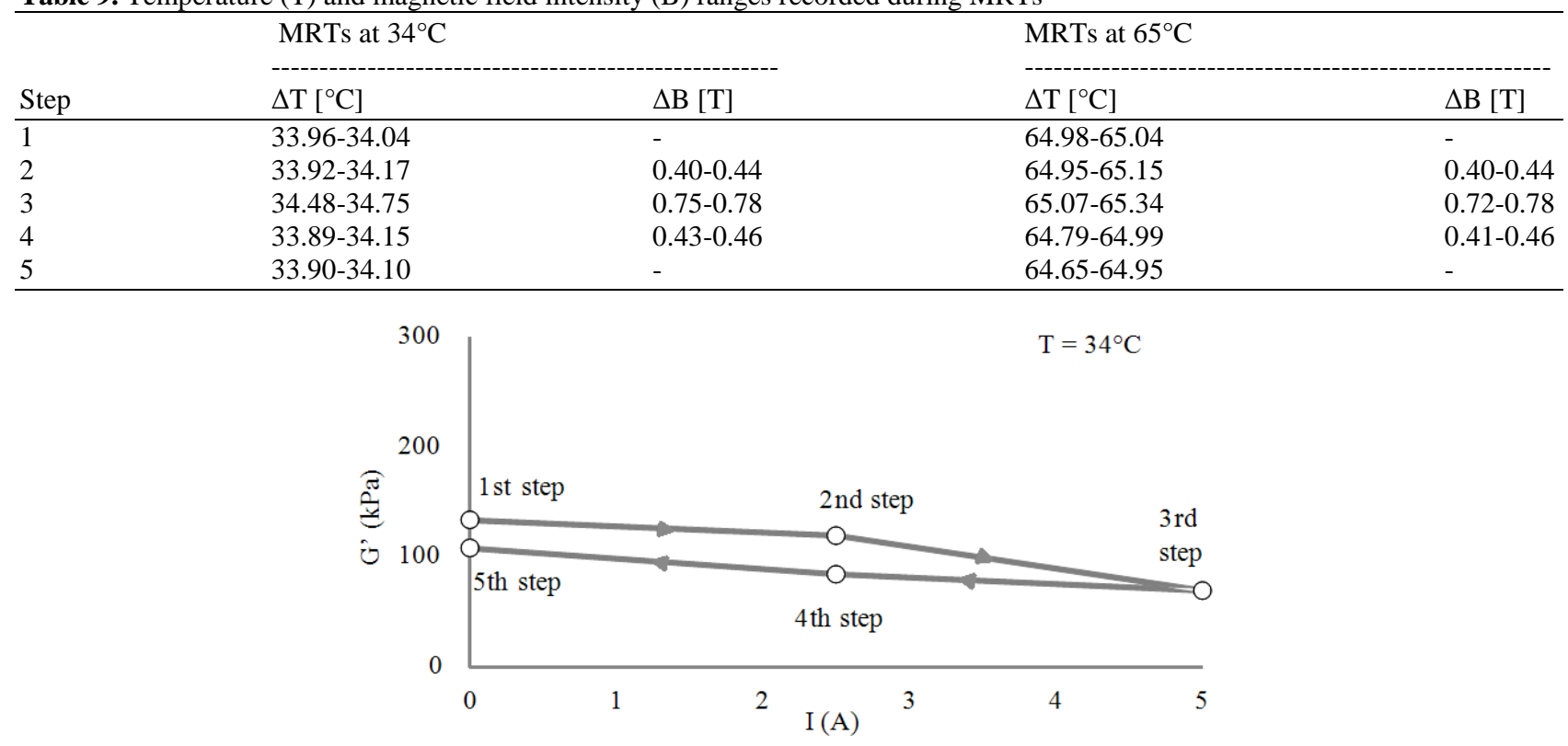

Fig. 3. Storage modulus versus imposed electric current obtained for neat bitumens (binder $\mathrm{B}, 34^{\circ} \mathrm{C}$ )

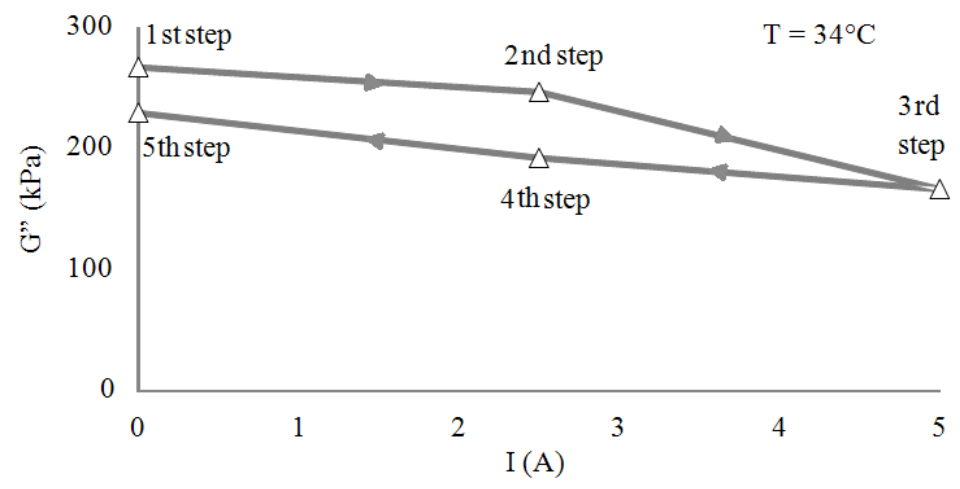

Fig. 4. Loss modulus versus imposed electric current obtained for neat bitumens (binder B, $34^{\circ} \mathrm{C}$ )



Fig. 5. Storage modulus versus imposed electric current obtained for neat bitumens (binder $\mathrm{B}, 65^{\circ} \mathrm{C}$ ) 
Ezio Santagata et al. / American Journal of Applied Sciences 11 (3): 505-519, 2014

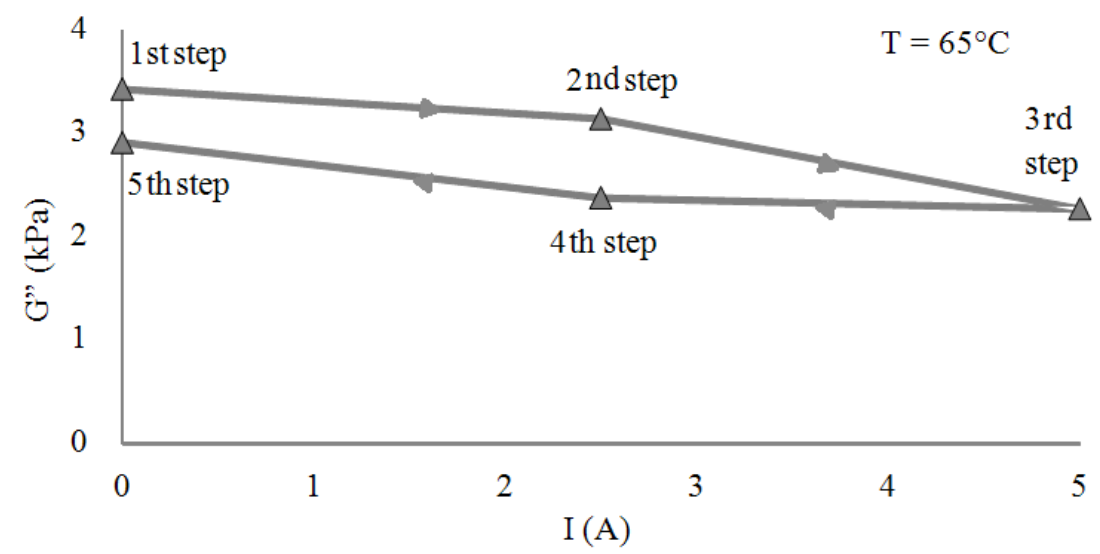

Fig. 6. Loss modulus versus imposed electric current obtained for neat bitumens (binder $\mathrm{B}, 65^{\circ} \mathrm{C}$ )

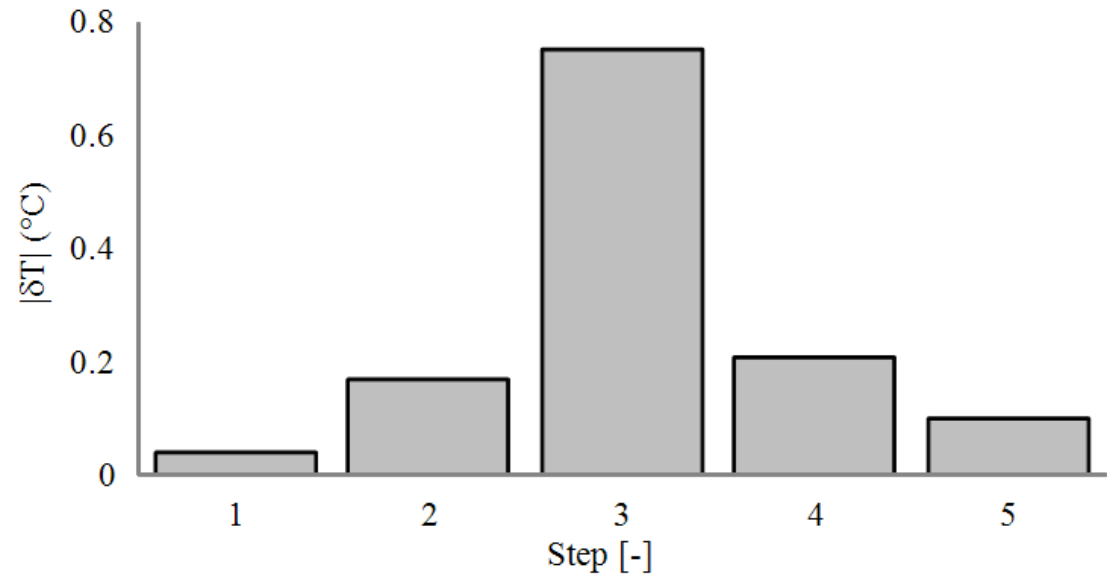

Fig. 7. Maximum deviations from target test temperatures

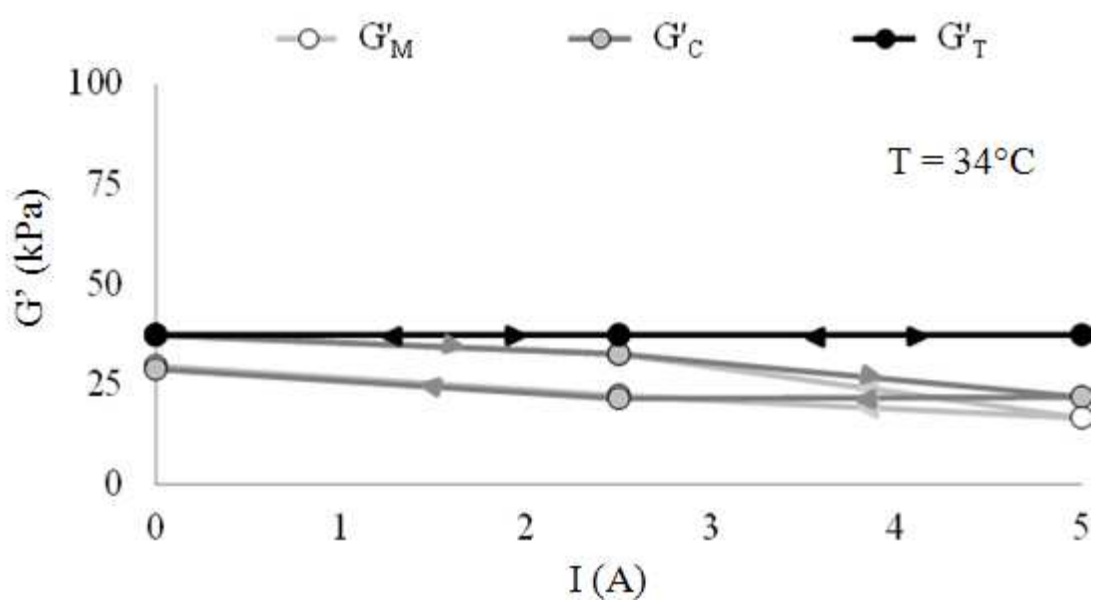

Fig. 8. Effect of overheating temperature correction on $\mathrm{G}^{\prime}$ of neat bitumens (binder A, $34^{\circ} \mathrm{C}$ ) 
Ezio Santagata et al. / American Journal of Applied Sciences 11 (3): 505-519, 2014

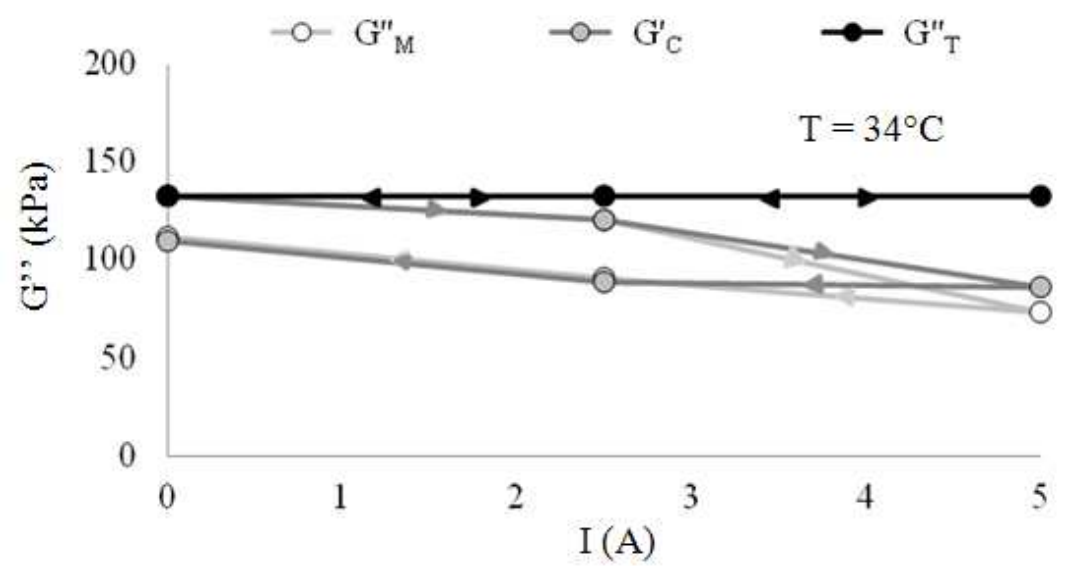

Fig. 9. Effect of overheating temperature correction on G" of neat bitumens (binder A, $34^{\circ} \mathrm{C}$ )

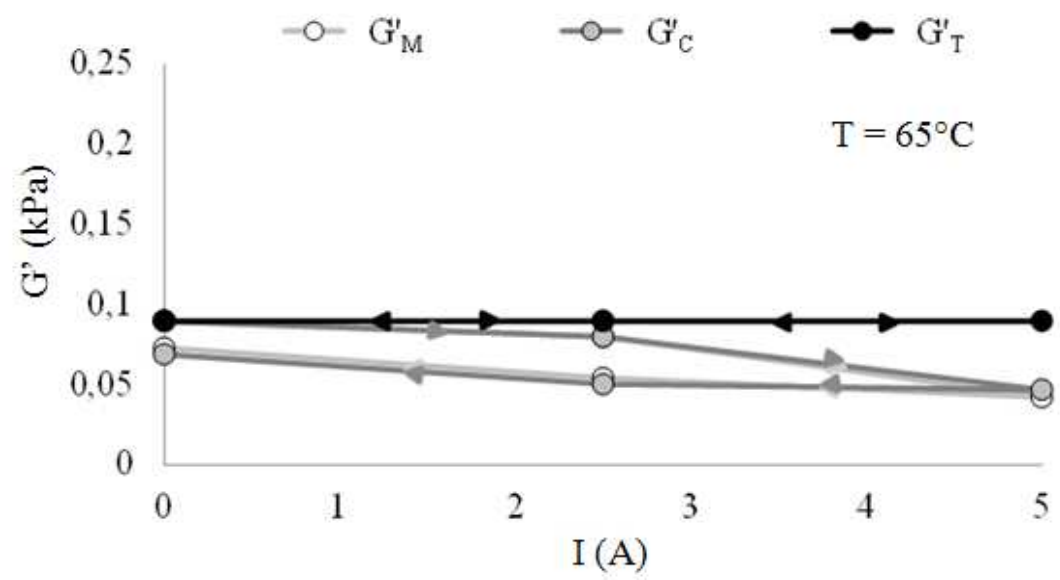

Fig. 10. Effect of overheating temperature correction on $\mathrm{G}^{\prime}$ of neat bitumens (binder $\mathrm{A}, 65^{\circ} \mathrm{C}$ )

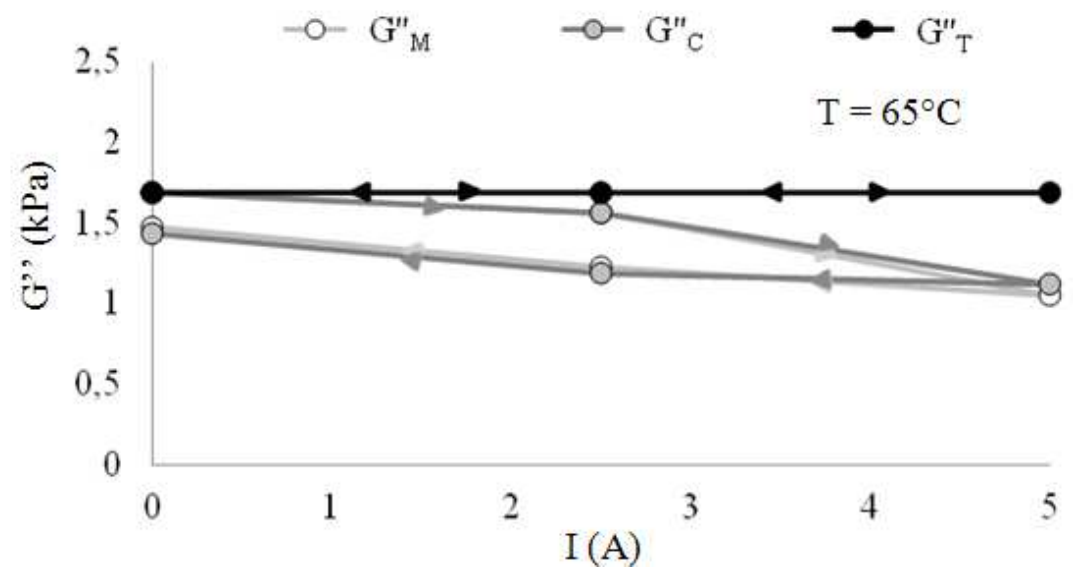

Fig. 11. Effect of overheating temperature correction on G' of neat bitumens (binder $A, 65^{\circ} \mathrm{C}$ ) 
Ezio Santagata et al. / American Journal of Applied Sciences 11 (3): 505-519, 2014

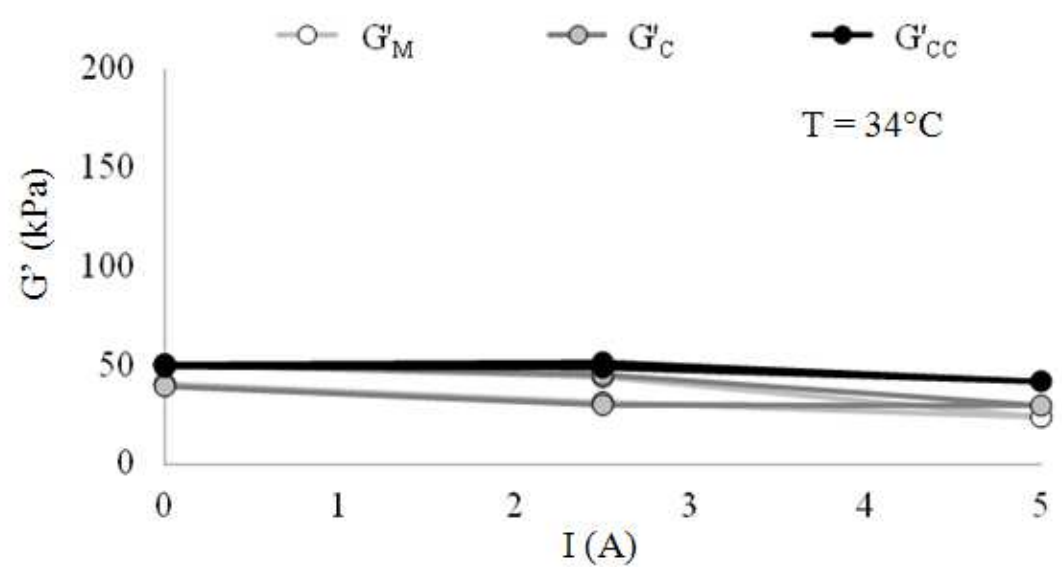

Fig. 12. Corrected G' of bitumen-additive blends (base binder A, $1 \% \mathrm{CNTs}, 34^{\circ} \mathrm{C}$ )

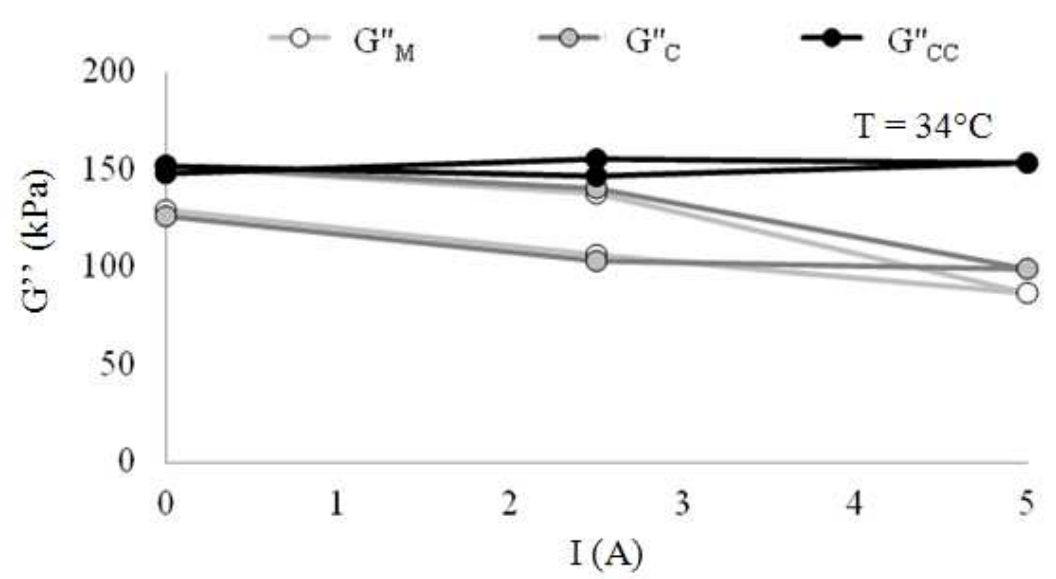

Fig. 13. Corrected G" of bitumen-additive blends (base binder A, $1 \% \mathrm{CNTs}, 34^{\circ} \mathrm{C}$ )

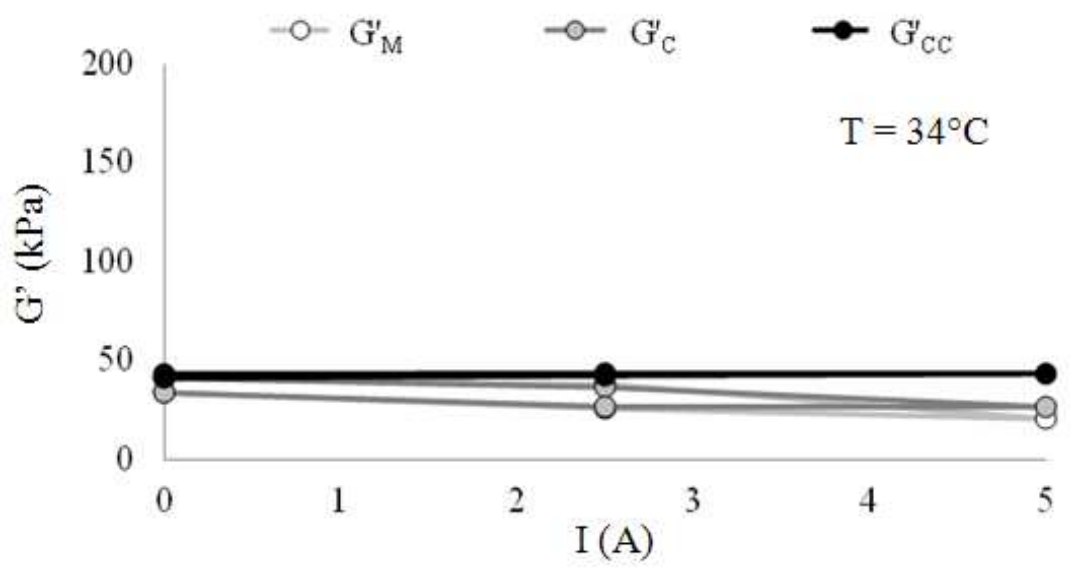

Fig. 14. Corrected G' of bitumen-additive blends (base binder A, $20 \% \mathrm{PF}, 34^{\circ} \mathrm{C}$ ) 
Ezio Santagata et al. / American Journal of Applied Sciences 11 (3): 505-519, 2014

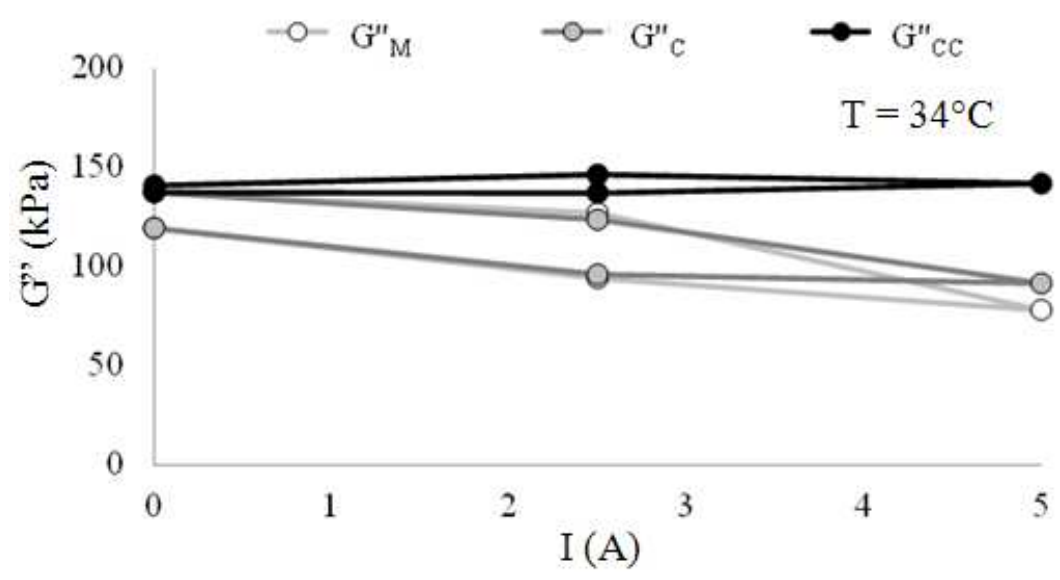

Fig. 15. Corrected G" of bitumen-additive blends (base binder A, $20 \% \mathrm{PF}, 34^{\circ} \mathrm{C}$ )

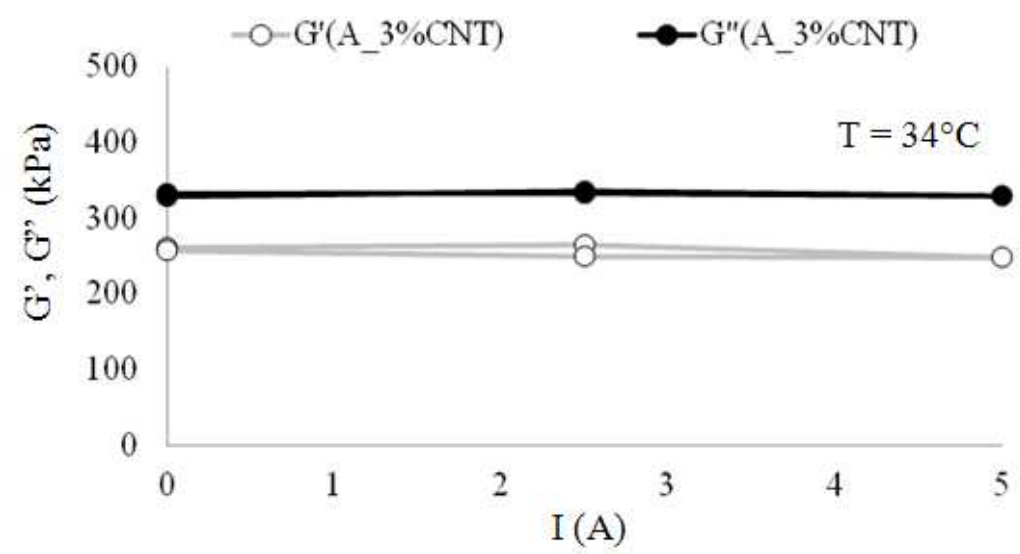

Fig. 16. Field sensitivity of bitumen-additive blends (base binder A, $3 \% \mathrm{CNTs}, 34^{\circ} \mathrm{C}$ )

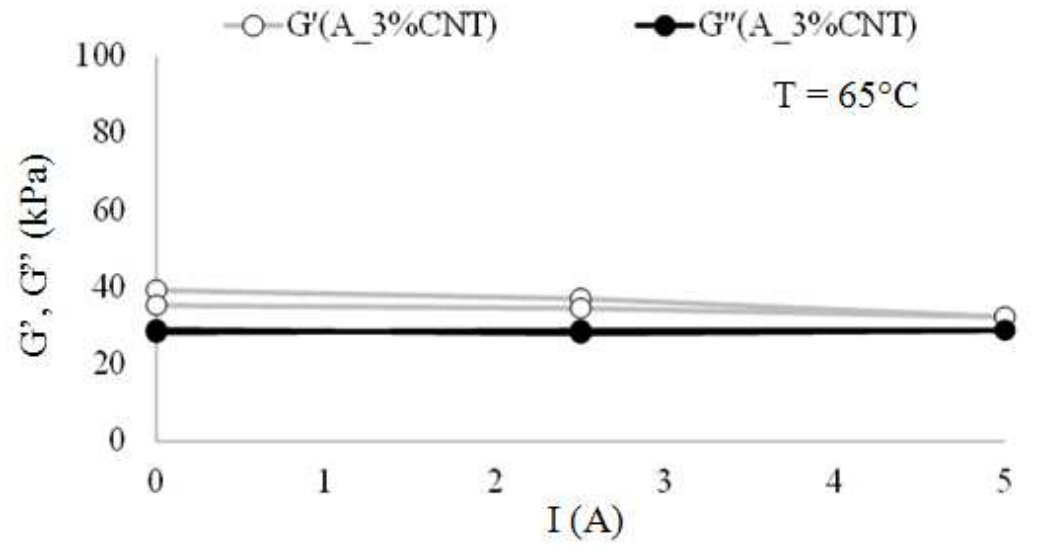

Fig. 17. Field sensitivity of bitumen-additive blends (base binder A, $3 \% \mathrm{CNTs}, 65^{\circ} \mathrm{C}$ ) 


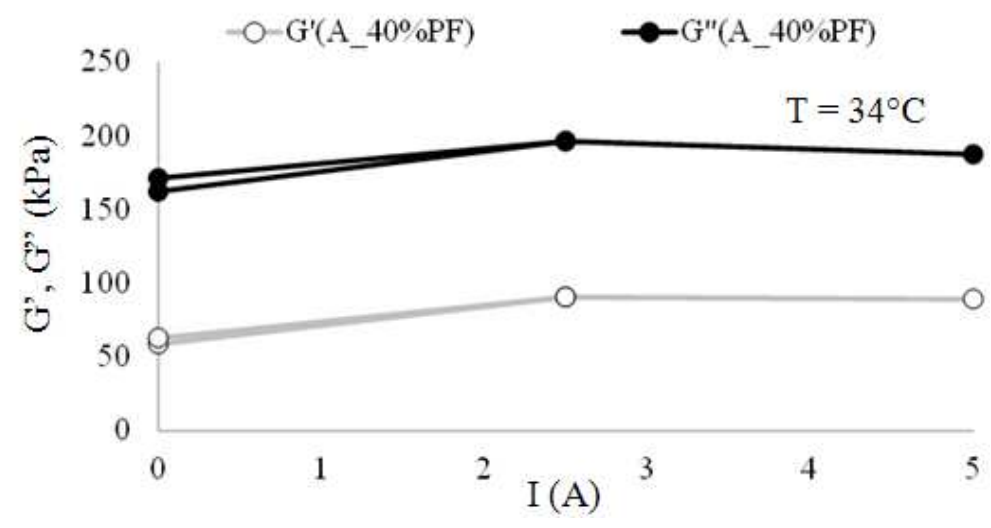

Fig. 18. Field sensitivity of bitumen-additive blends (base binder A, $40 \% \mathrm{PF}, 34^{\circ} \mathrm{C}$ )

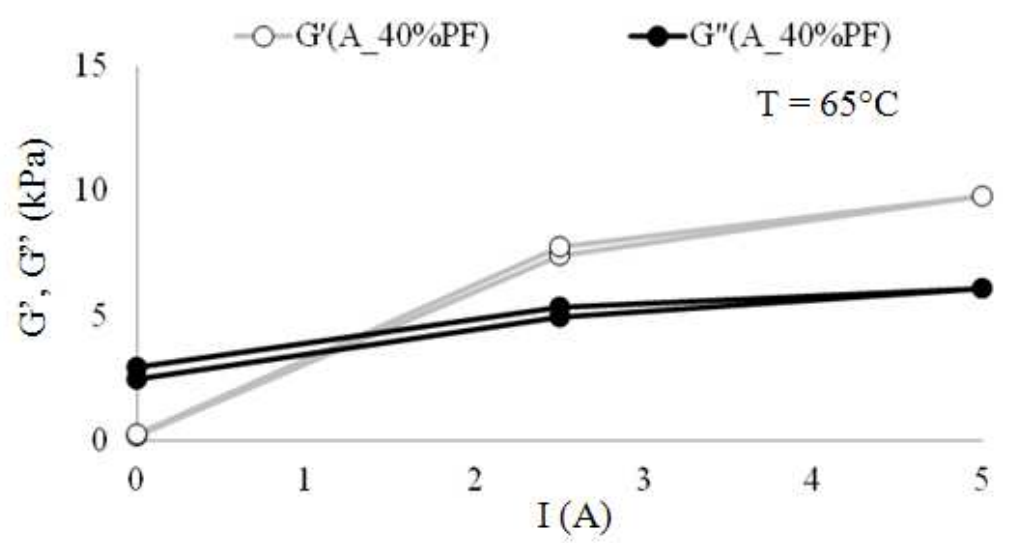

Fig. 19. Field sensitivity of bitumen-additive blends (base binder A, $40 \% \mathrm{PF}, 65^{\circ} \mathrm{C}$ )

In the case of CNTs, even with the higher dosage their addition to bitumen did not lead to any significant change in viscoelastic properties in the presence of magnetic fields (Fig. 16 and 17). Such an observation, which is in contrast with the results of several studies in which the magnetic characteristics of CNTs have proven to be relevant (Fang et al., 2009; 2012; Li et al., 2007), can be explained by referring to the peculiar structure and nature of the bitumen-CNT blends.

Particle reorientation may have been prevented by the extremely high flocculation forces which can be minimized only with a very stable dispersion of the additive within the bituminous matrix (Song and Youn, 2005; Ivanov et al., 2011; Fang et al., 2012). Moreover, in the presence of a highly viscous matrix, fieldresponsive phenomena may require very high magnetic fields (Hwang et al., 2011) which, however, are not compatible with the characteristics of the employed magneto-rheological device. Finally, part of the ineffectiveness of the CNTs can be attributed to their very high level of carbon purity (greater than 90\%), since recent studies carried out by Fang et al. (2009) have suggested that the magnetic properties of CNTs are mainly due to the residual iron catalyst resulting from the synthesis process, dramatically reduced after purification performed on commercially available products.

When $40 \%$ PF was added to base bitumens, rheological parameters seemed to be significantly affected by magnetic fields as proven by the substantial modulus increase (Fig. 18 and 19). This is in good agreement with findings of other research projects (Fang et al., 2009; Kuzhir et al., 2011; Guo et al., 2012).

By comparing results obtained at 34 and $65^{\circ} \mathrm{C}$ (Fig. 18 and 19), it can be observed that by means of $40 \% \mathrm{PF}$ addition superior magnetic properties were obtained at the higher test temperature. 
Table 10. Relative increments of storage and loss moduli for blends containing $40 \% \mathrm{PF}$ tested at $65^{\circ} \mathrm{C}$

\begin{tabular}{lcc}
\hline & Binder A $(\%)$ & Binder B (\%) \\
\hline$\Delta \mathrm{G}^{\prime}{ }_{2.5 \mathrm{~A}}$ & 39.2 & 67.2 \\
$\Delta \mathrm{G}^{,}{ }_{2.5 \mathrm{~A}}$ & 2.0 & 5.6 \\
$\Delta \mathrm{G}^{\prime}{ }_{5 \mathrm{~A}}$ & 51.8 & 88.2 \\
$\Delta \mathrm{G}^{\prime}{ }_{5 \mathrm{~A}}$ & 2.5 & 6.1 \\
\hline
\end{tabular}

This is probably the consequence of the lower viscosity of the carrier bituminous mediumwhich allows the formation of robust chain-like structures aligned with the direction of magnetic fields.

For these field-responsive blends, changes in the viscoelastic response were quantitatively assessed by introducing relative increments in storage and loss moduli $\left(\Delta \mathrm{G}^{\prime}{ }_{\mathrm{xA}}, \Delta \mathrm{G}^{\prime}{ }_{\mathrm{xA}}\right)$ calculated as indicated in Equation 5 and 6:

$$
\begin{aligned}
& \Delta \mathrm{G}^{\prime}{ }_{\mathrm{xA}}=\mathrm{G}_{\mathrm{xA}}^{\prime} / \mathrm{G}^{\prime}{ }_{0 \mathrm{~A}} \\
& \Delta \mathrm{G}^{\prime \prime}{ }_{\mathrm{xA}}=\mathrm{G}^{\prime \prime}{ }_{\mathrm{xA}} / \mathrm{G}^{\prime \prime}{ }_{0 \mathrm{~A}}
\end{aligned}
$$

where, $\mathrm{G}_{\mathrm{xA}}$ and $\mathrm{G}{ }_{\mathrm{xA}}$ are the complex modulus components at the generic $\mathrm{x}$ value of current $(2.5 \mathrm{~A}$ or 5 A) and $\mathrm{G}^{\prime}{ }_{0 \mathrm{~A}}$ and $\mathrm{G}^{\prime}{ }_{0 \mathrm{~A}}$ are the components evaluated in the absence of any magnetic field.

Average values of relative increments $\Delta \mathrm{G}^{\prime}{ }_{\mathrm{xA}}$ and $\Delta \mathrm{G}{ }_{\mathrm{xA}}$ calculated at the highest test temperature are given in Table 10, in which they are listed as a function of electric current intensity and base bitumen.

For both values of imposed electric current, relative increments of storage and loss moduli were found to be significantly higher in the case of blends prepared with base bitumen B (PG70-22), which was stiffer and more viscous than neat binder A (PG58-22). Thus, it can be postulated that the sensitivity of the PF additive to external magnetic fields is affected not only by the physical properties of the continuous bituminous matrix, but also by its composition (Table 1), which certainly has a direct effect on PF-bitumen interactions.

In agreement with other studies performed in the small strain domain (Fang et al., 2009; 2012), in the case of bituminous blends prepared with $40 \% \mathrm{PF}$, magnetic fields caused an enhancement of both storage and loss moduli. Increase in storage modulus, which was significantly higher than that in loss modulus, can be related to the effect of percolating aggregates which extend along the entire gap of the test specimen with a motion that follows that of the measuring system. On the contrary, increase in loss modulus can be associated to the out-ofphase movement of non-percolating aggregates and free branches (Kuzhir et al., 2011).

\section{CONCLUSION}

In the research presented in this study, the magnetorheological properties of several laboratory-prepared blends obtained from two different base bitumens combined with powder iron and multi-wall carbon nanotubes were evaluated.

Obtained results indicated that external magnetic fields can affect the storage and loss components of complex modulus to an extent which depends upon base bitumen and on additive type and dosage. However, analysis of experimental data highlighted the presence of biasing effects related to overheating phenomena and instrument limitations (inaccuracy in temperature and magnetic field control).

A simple procedure was developed to take into account the abovementioned temperature-related effects. Consequent results suggested the occurrence, in the case of blends containing the higher dosage of powder iron, of a structured chain-like arrangement within test specimens when subjected to an external magnetic field. Rather unexpectedly, such a phenomenon was observed to be more pronounced when employing a stiffer base bitumen. This indicates that magneto-rheological properties are strongly dependent upon physical and chemical interactions which take place between additives and bituminous matrix. Results obtained on other blends also revealed the crucial role played by magnetic field intensity, which was not sufficiently high to overcome the shielding actionof bitumen.

It can be concluded that future investigations on the magneto-rheological properties of bitumen-based binders certainly require the fine-tuning of test procedures with improvements in temperature regulation and magnetic field generation. Experimental data presented in this study also suggest that future development of pavement magnetic sensing techniques should consider the combined effects of temperature and field intensity.

\section{ACKNOWLEDGEMENT}

Part of the study reported in this study was developed within the FIRB research project on "Innovative nanostructured and polymer-modified bituminous materials" funded by the Italian Ministry of Education, University and Research (MIUR). The Authors are grateful to prof. Rajandrea Sethi who provided the magneto-rheological device employed in the investigation. 


\section{REFERENCES}

AASHTO, 2010. Performance-graded asphalt binder. American Association of State Highway and Transportation Officials, Washington, D.C.

Amirkhanian, A.N., F. Xiao and S.N. Amirkhanian, 2011a. Evaluation of high temperature rheological characteristics of asphalt binder with carbon nano particles. J. Test. Evaluat., 39: 1-9.

Amirkhanian, A.N., F. Xiao and S.N. Amirkhanian, 2011b. Characterization of unaged asphalt binder modified with carbon nano particles. Int. J. Pavement Res. Technol., 4: 281-286.

Bahia, H.U., D.I. Hanson, M. Zeng, H. Zhai and M.A. Khatri et al., 2001. Characterization of modified asphalt binders in Superpavemix design. NCHRP Report 459, National Academy Press, Washington, D.C.

Boyer, L. and E.V. Barrera, 2013. Asphalt bitumen modified with carbon nanotubes. Proceedings of the 2013 NSTI Nanotechnology Conference and Expo, NSTI-Nanotech, (NN '13), pp: 498-501.

Carlson, J.D. and J.L. Sproston, 2000. Controllable fluids in 2000-status of ER and MR fluid technology. Proceedings of the 7th International Conference on New Actuators, Bremen, Germany, (BG' 00), pp: 126-130.

Choi, H.J. and M.S. Jhon, 2009. Electrorheology of polymers and nanocomposites. Soft Matter, 5: 15621567. DOI: $10.1039 / \mathrm{b} 818368 \mathrm{f}$

Ellis, D.A.F., 2011. Aging facial skin: Lasers and related spectrum technologies. Facial Plastic Surgery Clinics North Am., 19: 229-440.

EN, 2009. Bitumen and bituminous bindersMeasurement ofdensity and specific gravityCapillary-stopperedpyknometer method. European Committee for Standardization (ECS), Brussels, Belgium.

Fang, F.F., H.J. Choi and M.S. Jhon, 2009. Magnetorheology of soft magnetic carbonyl iron suspension with single-walled carbon nanotube additive and its yield stress scaling function. Colloids Surfaces A: Physicochemical Eng. Aspects, 351: 46-51. DOI: 10.1016/j.colsurfa.2009.09.032

Fang, F.F., Y.D. Liu and H.J. Choi, 2012. Carbon nanotube coated magnetic carbonyl iron microspheres prepared by solvent casting method and their magneto-responsive characteristics. Colloids Surfaces A: Physicochemical Eng. Aspects, 412: 47-56. DOI: 10.1016/j.colsurfa.2012.07.013
Guo, C., X. Gong, S. Xuan, L. Zong and C. Peng, 2012. Normal forces of magnetorheological fluids under oscillatory shear. J. Magnetism Magn. Mater., 324: 1218-1224. DOI: 10.1016/j.jmmm.2011.11.013

Huang, J., L.Q. Zhang, Y. Yang and Y.Q. Wei, 2002. Analysis and design of a cylindrical magnetorheological fluid brake. J. Mater. Proc. Technol., 129: 559-562. DOI: 10.1016/S0924-0136(02)00634-9

Hwang, S., Y.B. Park, K.H. Yoon and D.S. Bang, 2011. Smart Materials and Structures Based on Carbon Nanotube Composites. In: Carbon NanotubesSynthesis, Characterization, Applications, Yellampalli, S. (Ed.), InTech, Shangai, China.

Ivanov, E., R. Kotsilkova, E. Krusteva, E. Logakis and A. Krytsis et al., 2011. Effects of processing conditions on rheological, thermal and electrical properties of multiwall carbon nanotube/epoxy resin composites. J. Polymer Sci. B: Polymer Phys., 49: 431-449. DOI: 10.1002/polb.22199

Kamila, S., 2013. Introduction, classification and applications of smart materials: An overview. Am. J. Applied Sci., 10: 876-880. DOI: 10.3844/ajassp.2013.876.880

Kang, T.J., K.H. Hong, B.W. Ahn and H.Y. Kim, 2011. Rheological behavior of magnetic carbon nanotubes and their application as kevlar coating. Fibers Polymers, 12: 366-370. DOI: 10.1007/s12221-0110366-z

Kciuk, M. and R. Turczyn, 2006. Properties and application of magnetorheological fluids. J. Ach. Mater. Manufact. Eng., 18: 127-130.

Kim, W.B., B.K. Min and S.J. Lee, 2004. Development of a padlessultraprecision polishing method using electrorheological fluid. J. Mater. Proc. Technol., 155-156: 1293-1299. DOI: 10.1016/j.jmatprotec.2004.04.239

Klingenberg, D.J., 2001. Magnetorheology: Applications and challenges. AIChE J., 47: 246-249. DOI: 10.1002/aic.690470202

Kordonski, W.I. and D. Golini, 1999. Fundamentals of magnetorheological fluid utilization in high precision finishing. J. Int. Mater. Syst. Struct., 10: 683-689. DOI: 10.1106/011M-CJ25-64QC-F3A6

Kuzhir, P., A.Gomez-Ramirez, M.T. Lopez-Lopez, G. Bossis and A. Zubarev, 2011. Non linear viscoelastic response of magnetic fiber suspensions in oscillatory shear. J. Non-Newtonian Fluid Mech., 166: 373-385. 
Lesueur, D., 2009. The colloidal structure of bitumen: Consequences on the rheology and on the mechanisms of bitumen modification. Adv. Colloid Interface Sci., 145: 42-82. DOI: 10.1016/j.cis.2008.08.011

Li, W.H., C. Lynam, J. Chen, B. Liu and X.Z. Zhang et al., 2007. Magnetorheology of single-walled nanotube dispersion. Mater. Lett., 61: 3116-3118. DOI: 10.1016/j.matlet.2006.11.045

Liu, Y., R.I. Davidson, P.M. Taylor, J.D. Ngu and J.M.C. Zarraga, 2005. Single cell magnetorheological fluid based tactile display. Displays, 26: 29-35. DOI: 10.1016/j.displa.2004.10.002

Motlagh, A.A., A. Kiasat, E. Mirzaei and F.O. Brigani, 2012. Bitumen modification using carbon nanotubes. World Applied Sci. J., 18: 594-599.

Nellensteyn, F.J., 1928. Relation of the micelle to the medium in asphalt. J. Instit. Petroleum Technol., 14: 134-138.

Petersen, S.W.J.C., R.E. Robertson, J.F. Branthaver, D.A. Anderson and D.W. Christensen et al., 1994. Binder characterization and evaluation. Strategic Highway Research Program, Washington, D.C.

Phule, P.P., 2001. Magnetorheological fluids: Principles and applications. Smart Mater. Bull., 2: 7-10. DOI: 10.1016/S1471-3918(01)80040-X

Pu, H.T., F.J. Jiang, Z. Yang, B. Yan and X. Liao, 2006. Effects of polyvinylpyrrolidone and carbon nanotubes on magnetorheological properties of ironbased magnetorheological fluids. J. Applied Polymer Sci., 102: 1653-1657. DOI: 10.1002/app. 24049

Rinaldi, C., A. Chaves, S. Elborai, X. He and M. Zahn. 2005. Magnetic fluid rheology and flows. Curr. Opin. Colloid Interface Sci., 10: 141-157. DOI: 10.1016/j.cocis.2005.07.004

Sakai, Y., 1988. The ECVT Electro Continuously Variable Transmission. SAE Technical.
Santagata, E., O. Baglieri, D. Dalmazzo and L. Tsantilis, 2009. Rheological and chemical investigation on the damage and healing properties of bituminous binders. J. Assoc. Asphalt Paving Technol., 78: 567596.

Santagata, E., O. Baglieri, L. Tsantilis and D. Dalmazzo, 2012. Rheological characterization of bituminous binders modified with carbon nanotubes. ProcediaSocial Behav. Sci., 53: 546-555. DOI: 10.1016/j.sbspro.2012.09.905

Santagata, E., O. Baglieri, L. Tsantilis and G. Chiappinelli, 2013. Effects of nano-sized additives on the high-temperature properties of bituminous binders: Acomparative study. In: International RILEM Symposium on Multi-Scale Modeling and Characterization of Infrastructure Materials, Stockholm, pp: 297-309. DOI: 10.1007/978-94-0076878-9_22

Singh, D.K., V.K. Jain and V. Raghuram, 2004. Parametric study of magnetic abrasive finishing process. J. Mater. Process. Technol., 149: 22-29.

Song, Y.S. and J.R. Youn, 2005. Influence of dispersion states of carbon nanotubes on physical properties of epoxy composites. Carbon, 43: 1378-1385. DOI: 10.1016/j.carbon.2005.01.007

Wen, W.J., X.X. Huang and P. Sheng, 2008. Electrorheological fluids: Structures and mechanisms. Soft Matter, 4: 200-210. DOI: 10.1039/b710948m

Xiao, F., A.N. Amirkhanian and S.N. Amirkhanian. 2011. Long-term ageing influence of carbon nanoparticles on the rheological characteristics of short-term aged asphalt binders. Int. J. Pavement Eng., 12: 533-541. DOI: 10.1080/10298436.2011.560267

Xue, W., W. Dong and L. Wang, 2012. A review and a perspective about pavement monitoring. Int. J. Pavement Res. Technol., 5: 295-302. 